\title{
Coding of Auditory Space
}

\section{M asakazu Konishi}

Division of Biology 216-76, California Institute of Technology, Pasadena, California

91125; email: konishim@caltech.edu

Key Words interaural time difference, interaural level difference, receptive field, place and ensemble coding

- Abstract Behavioral, anatomical, and physiological approaches can be integrated in the study of sound localization in barn owls. Space representation in owls provides a useful example for discussion of place and ensemble coding. Selectivity for space is broad and ambiguous in low-order neurons. Parallel pathways for binaural cues and for different frequency bands converge on high-order space-specific neurons, which encode space more precisely. An ensemble of broadly tuned place-coding neurons may converge on a single high-order neuron to create an improved labeled line. Thus, the two coding schemes are not alternate methods. Owls can localize sounds by using either the isomorphic map of auditory space in the midbrain or forebrain neural networks in which space is not mapped.

\section{INTRODUCTION}

The barn owl (referred to as owl hereafter) emerged as an excellent model for the study of sound localization because behavioral, anatomical, and physiological approaches can be integrated in this species. The last general review on sound localization in owls appeared in 1995 (Konishi 1995). The present review updates the information, emphasizing the new developments since 1995, although it cites older papers on owls for background information, as well as mammalian examples for comparison. One of the two main goals of owl research has been to find the anatomical and physiological mechanisms that confer on space-specific neurons their selectivity for sound source directions. The second aim has been to establish links between the response of space-specific neurons and the owl's sound-localizing behavior. The owl has also served as a model system for the study of plasticity in neural coding. This subject is outside the scope of the present article, and a recent review for this field is available (Knudsen 2002).

\section{ITD AND ILD FOR SOUND LOCALIZATION}

The interaural time difference (ITD) arises from a difference in the paths along which sound signals travel from its source to the two ears. Temporal disparities between the ears occur in different aspects of signals including onset time, phase of 
spectral components, and timing of amplitude modulation. The owl derives ITDs from the spectral components of complex signals. The interaural level difference (ILD) arises from differences in the amount of attenuation and amplification of signals between the ears. ILDs vary not only with the direction of sound sources but also with frequency. Frequency-dependent ILDs are referred to as spectral ILDs. In the owl's auditory space, ITD varies as a function of horizontal direction, or azimuth. On the other hand, ILD varies as a function of elevation for frequencies above about $4 \mathrm{kHz}$ because the left and right ear openings are vertically displaced from each other (Brainard et al. 1992, Moiseff 1989a). To show that owls use ITD and ILD for localization, we use a sensitive behavioral response. Owls rapidly turn their heads toward perceived sound sources in response to signals delivered by earphones. Early studies obtained a good linear relationship between ITD and the angle of head orientation in azimuth. The response of owls to ILD only indicated that the owls interpreted sounds louder in the left ear as "downwards" and those louder in the right ear as "upwards" (Moiseff \& Konishi 1981, Moiseff 1989b). Recent studies have used head-related transfer functions (HRTFs), which are based on signals recorded near the owl's eardrum as they arrive from different directions (Keller et al. 1998). These signals provide data for computation of ITDs and ILDs in addition to monaural signals. HRTFs obtained from other individuals under anesthesia are good enough to enable owls to localize sounds as predicted. Egnor (2000) was the first to compare the accuracy of localization in elevation between free-field (with a single speaker) and HRTF (with earphones) paradigms. The two owls she tested localized HRTF signals as accurately as free-field signals. The parameters of HRTF can be varied to test which of them is essential for localization in each coordinate. When ITD was set to a fixed value for all frequencies without changing other properties of HRTF, owls turned their heads in the direction predicted from the ITD (Pogoniatz et al. 2001). Comparison of spectral ILDs and flat ILDs (without frequency-specific variations) showed small differences in localization in elevation (Egnor 2000, Poganiatz \& Wagner 2001). Thus, the role of spectral ILDs in vertical localization appears to be minor, although spectral ILDs were thought to resolve ambiguities in the distribution of ILDs (Brainard et al. 1992). Early physiological studies indicated that the owl's auditory system processed ITD and ILD independently (Takahashi et al. 1984). Owls can localize binaurally uncorrelated signals in elevation but not in azimuth because owls can extract ILDs but not ITDs from such signals (Egnor 2001). On the other hand, using HRTF signals, Poganiatz \& Wagner (2001) found that the pattern of localization in elevation varied with azimuthal sites, which suggests that ITDs might influence localization by ILDs. This interpretation requires further studies. Finally, the role of monaural signals for localization may be considered. The most interesting of these signals is monaural spectral cues, which are attributable to frequency-specific attenuation or amplification that varies with source directions. Egnor (2000) used a method to alter monaural spectral cues without changing binaural spectral cues to show that owls could not use monaural spectral cues for localization. 


\section{PARALLEL PATH WAYS FOR ITD AND ILD}

This section outlines the owl's brain pathways that process ITD and ILD. The abbreviations for the names of different auditory areas of the owl vary somewhat between different authors. Most of these differences are in the number and case of characters in abbreviations such as ICX and ICX. This review uses a convention that standardizes the case and number of characters for abbreviations. Thus, two-word names such as nucleus angularis, nucleus magnocellularis, and inferior colliculus are abbreviated as NA, NM, IC, respectively. The subdivisions of IC, the external and central nuclei are represented by ICx and ICc, respectively. Different areas within a subdivision such as the core and lateral shell of ICc are referred to as ICcc and $\mathrm{ICcl}$, respectively. Note that the same anatomical names do not necessarily indicate homology between mammals and owls.

The primary auditory fiber divides into two branches, one of which innervates NM and the other NA. These two nuclei constitute the starting points of separate parallel pathways leading to the midbrain (Figure 1). NM axons and NL (nucleus laminaris) cell bodies form circuits for processing ITDs. NL projects to two higher stations, ICcc and the anterior part of the dorsal lateral lemniscal nucleus [LLDa, previously known as nucleus ventralis lemnisci lateralis, pars anterior, or VLVa (Wild et al. 2001)]. LLDa also projects to ICcc. NA neurons project to the posterior part of the dorsal lateral lemniscal nucleus [LLDp, previously known as nucleus ventralis lemnisci lateralis, pars posterior, or VLVp (Wild et al. 2001)] on the contralateral side. This is the first site where ILDs are processed. NA, LLDp, and ICcc project across the midline of the brainstem to ICcl. Thus, the ITD and ILD processing pathways converge on each other in ICcl. All the nuclei mentioned so far are tonotopically organized. ICcl projects to ICx, where different frequency bands converge on single neurons. This station contains a map of auditory space in which "space-specific" neurons respond to signals coming from particular directions. This directionality is attributable to the neuron's selectivity for combinations of ITD and ILD. ICx projects to the optic tectum to form an auditory-visual bimodal map of space. Another pathway, from ICcl to the thalamus and the forebrain, is mentioned below.

\section{PROCESSING OF ITDS}

\section{The Jeffress Model}

Jeffress (1948) proposed a simple model for encoding ITDs for sound localization. His model has had large impacts on hearing research (Joris et al. 1998). The model consists of an array of neurons that receive input by systematically graded axonal paths from the ipsi- and contralateral sides. The neurons act as coincidence detectors and fire maximally when spikes from the two sides arrive simultaneously. A coincidence occurs when the sum of acoustic and neural transmission delays on one side equals that on the other side, i.e., $A_{i}+N_{i}=A_{c}+N_{c}$, where $A$ indicates 


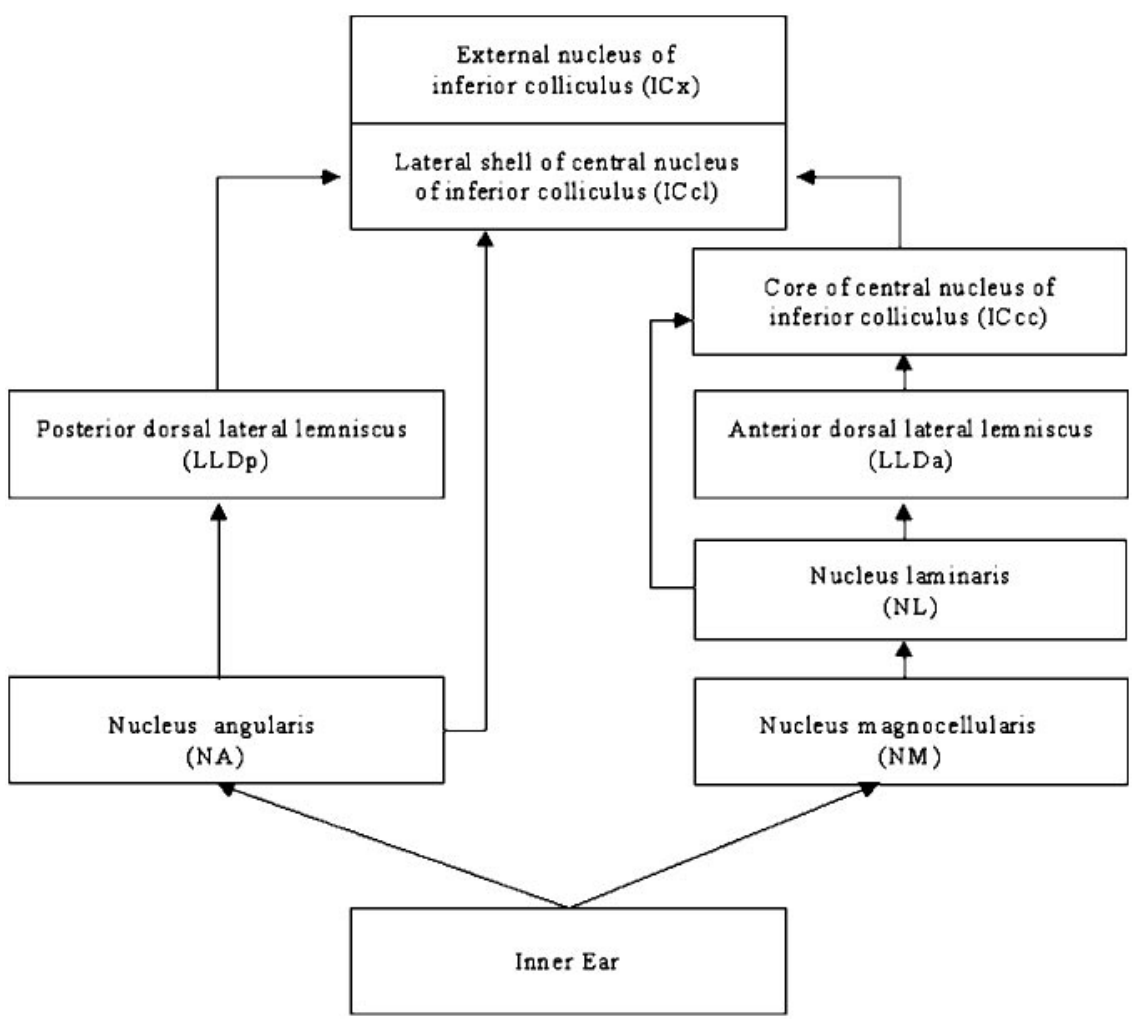

Figure 1 An outline of neural networks for processing ITD and ILD. See text for explanation (based on Carr \& Boudreau 1991; Takahashi \& Konishi 1988a,b; Takahashi et al. 1989; Wagner et al. 1987).

acoustic, $N$ neural delays, and subscript $i$ and $c$ ipsilateral and contralateral, respectively. $N_{c}$ and $N_{i}$ vary systematically so as to accommodate all biologically relevant ITDs. These properties and relationships in the model circuits allow certain predictions to be made. The difference in the arrival time of sound between the ears $\left|A_{i}-A_{c}\right|$ is $|\mathrm{ITD}|$, hence $|\mathrm{ITD}|=\left|N_{c}-N_{i}\right|$. Thus, the ITD to which a coincidence detector responds can be predicted from $N_{c}$ and $N_{i}$.

\section{Encoding ITD in the Brain}

The brain area where coincidence detection for ITDs occurs is the medial superior olive (MSO) in mammals and NL in birds. Isolating single neurons in vivo is notoriously hard in these areas. Few studies obtained more than several neurons per animal, making the discovery of internal organizations such as maps of ITDs difficult. All studies of coincidence detectors in laboratory mammals and owls have 
reported the following properties: (a) They receive phase-locked spikes as input; (b) they respond to monaural as well as binaural stimuli; (c) the spike rate of the coincidence detectors is not all or nothing but continuously graded according to the degree of coincidence (dog: Goldberg \& Brown 1969; owl: Sullivan \& Konishi 1984, Carr \& Konishi 1990, Peña et al. 1996, Viete et al. 1997; cat: Yin \& Chan 1990; gerbil: Spitzer \& Semple 1995; rabbit: Batra et al. 1997). The Jeffress model did not include these three properties except to stipulate that a spike represented each cycle of the stimulus tone. However, these properties turned out to be useful for further understanding of coincidence detection. The graded nature of coincidence detection and the use of phase-locked spikes give rise to periodic ITD response curves. One can derive $N_{c}$ and $N_{i}$, hence the most favorable ITD of the neuron, from phase-locked spikes of the two sides because coincidence detectors respond to monaural stimuli (Yin \& Chan 1990).

The discovery of the anatomical substrates for delay lines and coincidence detection required systems simpler than the mammalian cochlear nuclei and superior olivary complex. Parks \& Rubel (1975) were the first to suggest that the neural circuits formed by axons from NM and cell bodies of NL in domestic chickens might work like the Jeffress model. The axons and their collaterals from the ipsilateral NM enter the dorsal surface of the monolayer (Jhaveri \& Morest 1982, Young \& Rubel 1983). These axonal paths do not appear to provide variable delays, whereas the axons from the contralateral NM contact NL neurons at different points from medial to lateral along the ventral surface of the monolayer (Smith 1981). Subsequent studies with brain slices from chick embryos showed not only coincidence detection by NL neurons but also the possible role of the contralateral afferent fibers as delay lines (Overholt et al. 1992, Joseph \& Hyson 1993).

The size and structure of NL vary between acoustic specialists like barn owls and nonspecialists like chickens (Carr \& Friedman 1999, Carr \& Code 2000). $\mathrm{NL}$ occupies a larger volume of tissue than any other nucleus in the medulla of owls. The nucleus is approximately $1 \mathrm{~mm}$ thick, unlike the monolayer design of the chicken (Carr \& Boudreau 1993). The developing NL of barn owls resembles that of chickens. Both the monolayer design and the bipolar arrangement of dendrites in the chicken's NL cell bodies are transformed into the owl pattern later in development (Carr \& Boudreau 1996, Kubke \& Carr 2000, Kubke et al. 2002). Tracing labeled axons, Carr \& Konishi $(1988,1990)$ showed how the axons from NM innervate NL neurons. Unlike the chicken's NM, in which the axons from the ipsilateral side do not seem to serve as variable delay lines, the homologous fibers in the owl do. Single-unit recordings showed that the delay of spike transmission along the dorsoventral axis varied systematically with the position of the recorded axon for both the ipsilateral and contralateral fibers. The range of delays was consistent with the range of ITDs $(0-160 \mu \mathrm{s})$ that the owl uses. To accommodate this range with 1-mm-long axons, the speed of spike transmission needs to be slow. Spikes travel more slowly in thin axons than in large axons. Also, a short internodal distance conveys spikes more slowly than a long one. The part of the NM axons that is within NL is not only thin but also has short internodal distances (Carr \& 
Konishi 1990). However, the measurement of depth-dependent transmission times alone does not prove that NL neurons receive spikes by systematically graded axonal paths.

A recent study recorded two NL neurons consecutively with the same electrode to determine changes in ITDs with the depth of recording sites from the dorsal border (Peña et al. 2001). When the data were corrected for the difference in the angle of electrode penetration, the delays calculated from the changes in ITD and depth closely resembled those reported by Carr \& Konishi (1990). These results provide further evidence for the claim that ITDs are mapped along the dorsoventral axis of the owl's NL, which is orthogonal to the tonotopic axis. Delays in both the ipsilateral and contralateral NM axons vary similarly as a function of distance from the dorsal and ventral borders, respectively. This configuration resembles the Jeffress model in which both $N_{i}$ and $N_{c}$ vary systematically. Yet, NL mostly represents the contralateral hemifield with a small excursion into the ipsilateral hemifield. Most neurons are tuned to ITDs in which the sound in the contralateral ear leads that in the ipsilateral ear. Neurons tuned to ITD $=0$ are closer to the ventral border of the nucleus than to the midpoint between the two borders. If we assume that spikes travel slower or over longer paths on the contralateral side, we can explain the location of ITD $=0$. We do not know whether stimulus-evoked spikes arrive simultaneously at the dorsal and ventral borders of NL.

The neural circuits that contain delay lines and coincidence detectors have also been studied in cats (Smith et al. 1993). MSO is a sheet of cells that is oriented parallel to the mid-sagittal plane of the brain. Spherical bushy cells of the anterior ventral cochlear nucleus (AVCN) provide delay lines for MSO neurons. Smith et al. (1993) found that only the axonal paths from the contralateral AVCN varied systematically. However, a more recent study by Beckius et al. (2000) reports that both the contralateral and ipsilateral axons contact MSO neurons in a graded manner. Statistical analyses of distributions of ITDs obtained from different cats suggested that ITDs tended to vary systematically in MSO (Yin \& Chan 1990). The most favorable ITD of a neuron appears to change from 0 near the posterior end of the nucleus to larger contralateral-leading ITDs as the recording site shifts toward the anterior end (Joris et al. 1998).

\section{The Role of Inhibition}

The coincidence detectors in the Jeffress model receive only excitatory inputs. However, the coincidence detectors in both MSO and NL receive inhibitory inputs (Carr et al. 1989; Grothe \& Sanes 1993, 1994; Bruckner \& Hyson 1998; Funabiki et al. 1998). Nucleus laminaris of both chickens and owls receives GABA (gammaaminobutyric acid) -mediated inhibitory input (Carr et al. 1989, Lachica et al. 1994). The source of the inhibitory input is known to be the superior olivary nucleus (SO) in the chicken (Lachica et al. 1994, Bruckner \& Hyson 1998, Yang et al. 1999). In chicken embryos, electrical stimulation of the inhibitory fibers from SO inhibits NL neurons in vitro. Since these fibers cannot follow electrical 
pulses separated by short intervals, the signals they convey are likely to have no effect on the timing of the coincidence detectors (Yang et al. 1999). In the owl's NL, injection of GABA reduces the height of multi-unit ITD peaks without affecting their temporal aspect. Thus, gain control is likely to be the main function of GABA-mediated inhibition (Peña et al. 1996, Takahashi \& Konishi 2002). In small mammals such as gerbils and some bats, inhibitory input to MSO appears to do more than gain control (see Grothe 2000 for review). However, the inhibitory synapses do not appear to receive phase-locked spikes (Spitzer \& Semple 1995), although a recent study claims otherwise (Brand et al. 2002). In an in vitro study, MSO neurons of gerbils were sensitive for a specific interstimulus interval and were selectively inhibited at other time differences (Grothe \& Sanes 1994).

\section{Temporal Resolution}

NM and NL in chicks and owls show a number of morphological and physiological adaptations for time coding such as end bulb-type terminals in NM, nonlinear current-voltage relationships near the resting potential, and rapidly activating and slowly inactivating potassium currents (Carr \& Boudreau 1991; see Carr \& Friedman 1999, Trussel 1999 for review; Parameshwaran et al. 2001). Similar adaptations in the ventral cochlear nucleus are also known, from which spherical bushy cells innervate MSO (see Oertel 1999 for review). Models such as those proposed by Agmon-Snir et al. (1998) and Simon et al. (1999) may work for chickens that operate in relatively low sound frequencies. Owls use relatively high frequencies for sound localization. More than half of the length of the owl's basilar membrane is devoted to frequencies between $5 \mathrm{kHz}$ and $10 \mathrm{kHz}$ (Köppl et al. 1993). Also, unlike the mammalian species studied so far, the owl's primary auditory fibers show phase-locking at frequencies as high as $9-10 \mathrm{kHz}$ (Sullivan \& Konishi 1984, Köppl 1997b). For these frequencies, jitter in the cross-synaptic transmission of phase-locked spikes alone can reduce the temporal resolution of the neural circuits for coincidence detection. In the owl, a single NL neuron may receive as many as 40-150 axons from each side, although we do not know whether these axons come from a single neuron or multiple neurons (Carr \& Boudreau 1993). If these axons are from different NM neurons, an ensemble of neurons can represent all stimulus cycles by phase-locked spikes. This condition further increases temporal jitter.

Unlike the bipolar design of dendrites in the chicken's NL, the dendrites are short and not organized into two separate groups in the owl's NL. The question is how the owl's NL neurons discriminate between coincidences of spikes from the same side and those from the two sides. Reyes et al. (1996) suggested for chicks a simple mechanism that might solve this problem. They injected currents into NL neurons in vitro to vary the membrane potential so as to create a waveform that results from the superposition of two sine waves. The spike rate was maximal when the waveform simulated two sine waves in phase. When the two were out of phase, the spike rate was smaller than that elicited by monaural stimulation. 
This experiment shows that separation of ipsilateral and contralateral postsynaptic potentials is not necessary. However, currents elicited by tonal stimuli may or may not behave like the current injected by the electrode.

\section{Delay Lines-Coincidence D etectors as Cross-Correlators}

The circuits formed by NM axons and NL cell bodies carry out a computation similar to cross-correlation. For time-varying functions, cross-correlation measures how well the two functions match as a function of temporal disparity between them. The degree of match is represented by the sum of the products of multiplication of the two functions for all sampling intervals and is largest when the two functions are perfectly aligned. The spike rate of a neural coincidence detector for the most favorable ITD tends to be greater than the sum of the spike rates for the same monaural stimuli that were used to make the binaural stimuli. In contrast, the spike rate for the least favorable ITD tends to be smaller than either of the monaural spike rates (e.g., Goldberg \& Brown 1969, Yin \& Chan 1990, Peña et al. 1996). These relationships suggest multiplications of monaural inputs by a factor larger than 1 for the response to the favorable ITD and less than 1 for the response to the least favorable ITD. Whether the multiplication by less than 1 involves inhibition or not has been discussed, but computer models of coincidence detection by MSO neurons could produce typical cyclical ITD responses without any inhibition (Colburn et al. 1990; Han \& Colburn 1993; see also Reyes et al. 1996).

The effects of cross-correlation by the primary coincidence detectors manifest themselves in behavior and high-order neurons. Jeffress et al. (1962) carried out an experiment to show that humans cross-correlated binaural signals to detect ITDs for localization. Listening to broadband signals delivered by earphones, their subjects perceived an acoustic "image" somewhere between the ears. The subjects' task was to bring the image to the midpoint between the ears by controlling the timing of the signals. For example, they changed the ITD by $100 \mu$ s to see if it moved the image to the center. Repeated trials by each individual gave the data for calculating the mean and standard deviation of the selected delays. The investigators varied the degree of correlation or similarity between the signals by adding random noise (Jeffress \& Robinson 1962). The image normally blurs as the two signals are decorrelated, which makes it hard to localize precisely (Blauert \& Lindeman 1986). The subjects were remarkably good at localizing partially correlated signals. The standard deviation remained small until the degree of correlation declined to about 0.3 . We conducted similar experiments in barn owls, using their head-turning responses induced by broadband signals delivered by earphones (Saberi et al. 1998b). The owls turned their heads toward the spatial direction expected from the ITD contained in the signals. The standard deviation of the mean spatial angles served as the measure of localization accuracy. As in humans, the standard deviation remained small until the degree of correlation declined to 0.3 . 
The main advantage of using owls in this type of experiment is the possibility to look for the neural correlates of behavioral phenomena using the same stimuli. Albeck \& Konishi (1995) carried out systematic studies of neuronal responses to partial correlations along the ascending ITD processing pathway. The responses of space-specific neurons in ICx most closely resembled the behavioral observation. These neurons responded maximally to a perfectly correlated pair of broadband signals. Their spike rates declined as a function of decorrelation. Assuming that the detection of an ITD depends on both the number of neurons tuned to it and the amount of response, Saberi et al. (1998b) derived a relationship between signal detectability and the degree of correlation for space-specific neurons in the optic tectum that receive direct input from ICx neurons (Knudsen \& Knudsen 1983). The shape of the curves so obtained, when inverted, resembled the distribution of standard deviations in the behavioral studies mentioned above. Cross-correlation also facilitates the discrimination of different sound sources. Keller \& Takahashi (1996) studied the ability of space-specific neurons to discriminate between two simultaneously active sound sources in free-field. The neurons responded separately to the two speakers when they were emitting uncorrelated signals, whereas they responded to phantom sources between the real sources when the two signals were correlated.

\section{Frequency Convergence in the Processing of ITD}

Owls cannot localize single tones unambiguously because they cannot discriminate between ITDi and ITDi \pm nT, where ITDi is a frequency-independent ITD, $\mathrm{n}$ is an integer, and $\mathrm{T}$ is the period of the stimulus tone (Saberi et al. 1998a, 1999). The neuronal coincidence detectors also respond to ITDi and ITDi $\pm n T$, which appear as multiple peaks in ITD curves. This phenomenon is referred to as phase-ambiguity in the owl literature or cyclicity in the mammalian literature. It is attributable to the fact that these neurons selectively respond to interaural phase differences (IPDs). Note that addition to or subtraction of T from an ITD does not change the IPD. However, there must be an ITD that does not vary with frequency because $N i$ and $N c$ are independent of frequency. The ITDi is also referred to as the characteristic delay (CD) (Rose et al. 1966). Yin \& Kuwada (1983) developed a quantitative method to derive the CD from ITD curves for different frequencies. In ITD curves, the peak at ITDi is referred to as the main or best peak, and the peaks at ITDi $\pm \mathrm{T}$ are called the side peaks.

The space-specific neurons respond most strongly to the ITDi conveyed by broadband signals (Figure 2). Thus, the transformation from the primary coincidence detectors to the space-specific neurons needs to be explained. This derivation cannot be achieved without convergence of different frequency bands (Mazer 1998). Cross-correlation of complex waveforms is the same as the sum of cross-correlations performed on the separate frequency bands of the original waveforms. Evidence indicates that the cat's low-frequency MSO neurons sum the results of cross-correlation for different frequency bands of complex signals 


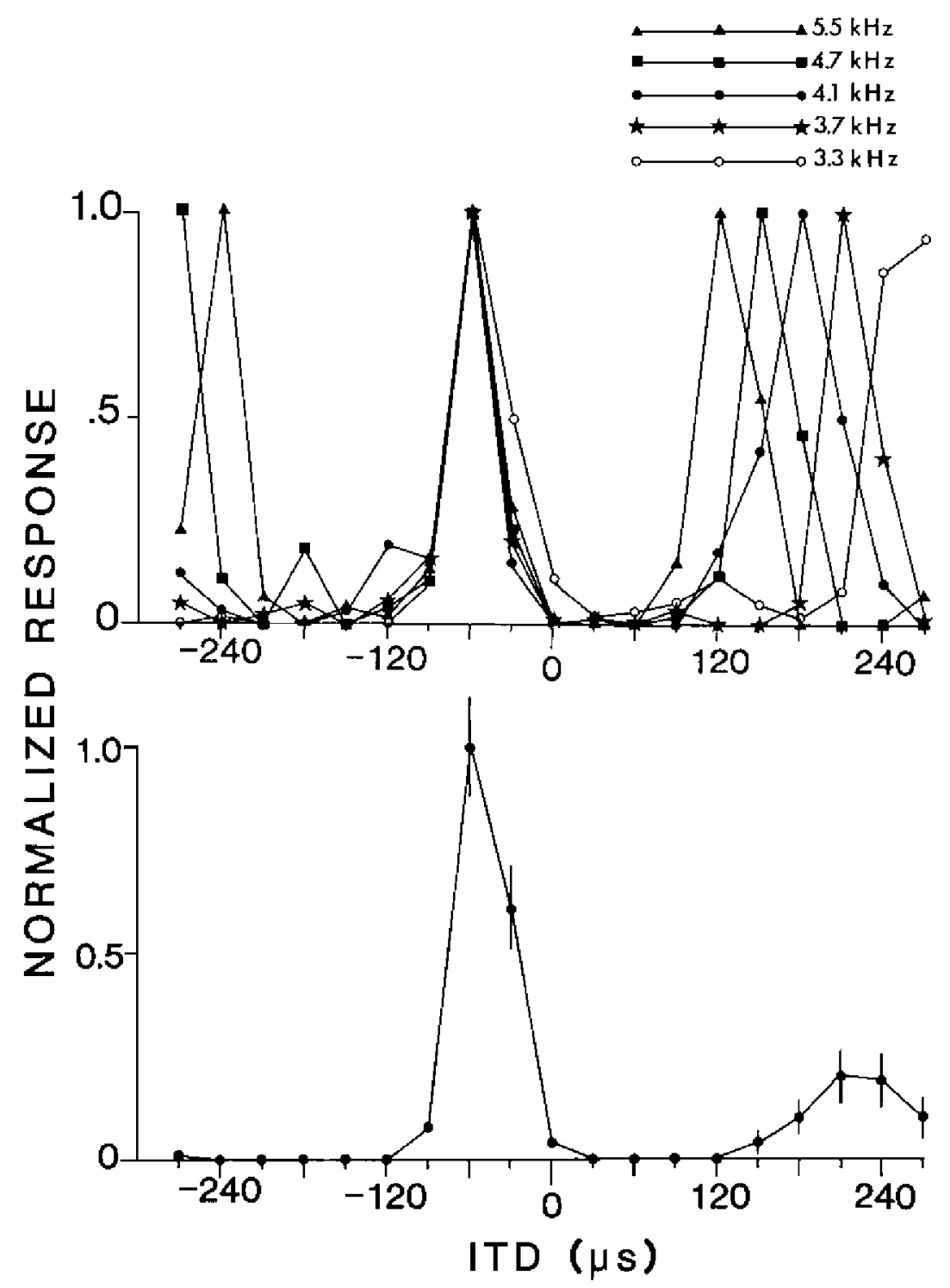

Figure 2 Response of a space-specific neuron to ITD in different frequencies. The top panel shows ITD curves for different frequencies. All five curves converge at the frequency-independent ITDi of $-60 \mu$ s. The side peaks are systematically separated according to the stimulus frequency. Note that the width of ITD curves does not vary much with frequency. The lower panel shows the response of the same neuron to the same ITDi in a broadband signal (from Takahashi \& Konishi 1986). 
(Yin \& Chan 1990). A similar phenomenon also occurs in IC because it is relayed from MSO (Yin et al. 1986, 1987). Such summation can resolve the phaseambiguity, depending on the bandwidth of both neurons and signals. In MSO and IC of cats, a broadband signal causes the main peak to become slightly higher than the side peaks (Yin et al. 1986, 1987). However, the side peaks do not disappear except at large ITDs because both MSO and IC neurons are narrowly tuned to frequency. Few studies of the mammalian IC have analyzed ITD-sensitive neurons that are broadly tuned to frequency. When a space-specific neuron's ITD curves for different frequencies are compared, the peaks align at ITDi, the side peaks being misaligned (Figure 2) (Takahashi \& Konishi 1986). When these ITD curves are summed with respect to ITDi, the resulting curve has the highest peak at ITDi (Figure 3).

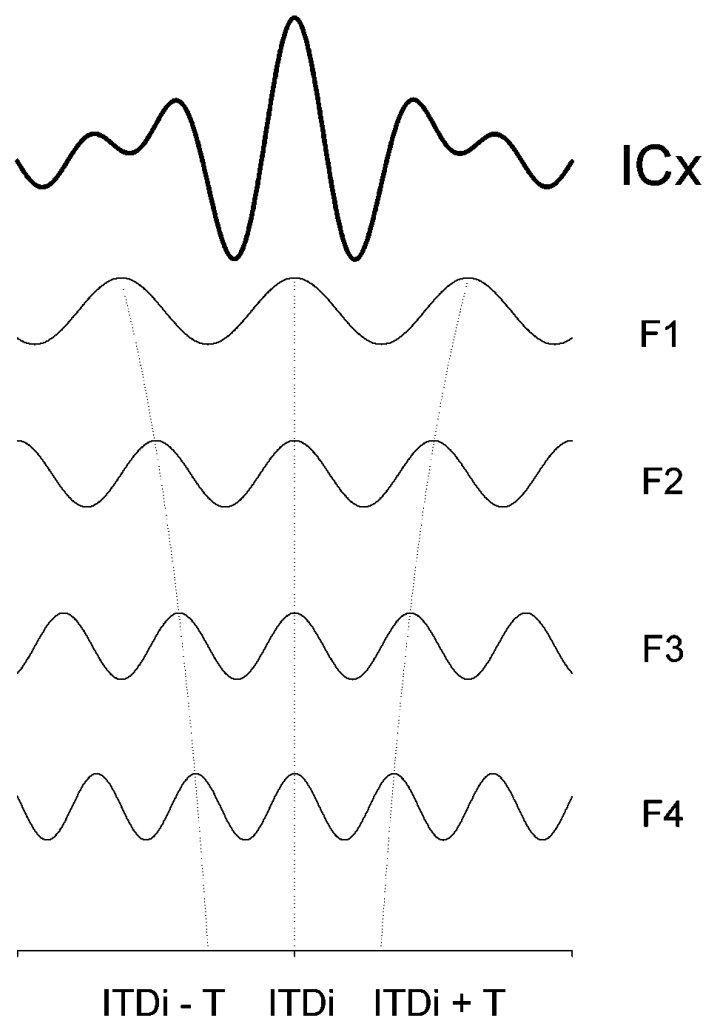

Figure 3 Frequency convergence. ICx neurons receive ITD carrying input from ICcl neurons tuned to different frequencies (F1, F2, etc.). The straight line connecting the ITD curves of different frequencies indicates the frequency independent ITDi. Note that addition of ITD responses (thick line) across frequency gives rise to a tall peak at ITDi and smaller peaks at other ITDs. However, this process alone does not discriminate between the peaks (from Peña \& Konishi 2000). 
The question is how to discriminate between the main and side peaks after summing ITD curves for different frequencies. Albeck \& Konishi (1995) suggested that setting the threshold of firing below the main peak but above the side peaks should accomplish the task. This idea finds support in recent intracellular studies of these neurons (Peña \& Konishi 2002). Postsynaptic potentials induced by broadband ITD-containing signals in these neurons showed multiple peaks corresponding to ITDi and ITDi \pm nT. Here, the main peak was only slightly taller than the side peaks. However, the spike output of the same neurons showed much greater differences between the main and side peaks. Some neurons had only the main peak and others had a large main peak and much smaller side peaks. These differences are attributable to the setting of spiking thresholds (Figure 4). Local injection of bicuculline in ICx exposes the side peaks and widens the ITD peaks (Fujita \& Konishi 1991, Mori 1997). The blocker presumably causes a rise in the resting potential of the neurons, bringing it closer to the spike threshold. Thus, a combination of frequency convergence, inhibition, and thresholding is responsible for the resolution of phase ambiguity.

A phenomenon similar to the response of space-specific neurons to tones occurs in human psychoacoustics. Humans cannot localize the source of low-frequency tones unambiguously. Trahiotis \& Stern (1994) proposed a model to account for the ability of humans to localize broadband signals. They suggested that humans align the results of cross-correlation on different frequency bands as in the owl's auditory system. If the results are aligned with respect to ITDi, then only the line connecting the peaks at ITDi is straight, and all other lines connecting the peaks at ITDi $\pm \mathrm{nT}$ are curved. They argued that the straight line would distinguish ITDi from ITDi $\pm \mathrm{nT}$ (cf. Figure 3). Proximity to ITD $=0$ was also suggested as an additional criterion that helps discriminate between ITDi and ITDi \pm nT.

\section{Processing of ILDs}

We originally thought that NM and NA neurons were completely different; the former phase-locking and insensitive to stimulus intensity and the latter poorly phaselocking and sensitive to stimulus intensity (Sullivan \& Konishi 1984, Sullivan 1985). NM neurons are apparently not as insensitive to variations in intensity as we thought. The main difference between the two nuclei is in the rate of spontaneous discharge, which is low in NA and high in NM (Köppl 1997a). Also, NA contains several morphologically and physiologically distinct neuron types (C. Köppl and C.E. Carr, submitted). Some of these neurons phase-lock quite well for frequencies below $5 \mathrm{kHz}$. Nevertheless, the pathway that starts in NA is for ILD processing, although NA may also be the starting point of pathways for other functions.

ILDs are initially processed in the lateral superior olivary nucleus (LSO) in mammals and in the LLDp in the owl. LLDp receives excitatory input from the contralateral NA and inhibitory input from the contralateral LLDp (Takahashi \& Keller 1992, Adolphs 1993). LLDp neurons respond best to contralateral input 
alone, and their spontaneous activities are reduced or extinguished by ipsilateral input alone. The response of these neurons varies, therefore, as a function of ILDs. However, the relationship between excitatory and inhibitory inputs is not constant but varies systematically from dorsal to ventral in the nucleus (Manley et al. 1988, Adolphs 1993, Mogdans \& Knudsen 1994). Both the sensitivity for ipsilateral input and the degree of inhibition decrease along this axis. This trend is also correlated with the density of fiber terminals from the contralateral side (Takahashi et al. 1995). These physiological and anatomical attributes give rise to maps of ILD in this nucleus. In higher centers such as ICcl and ICx, the neurons have pyramidshaped ILD curves. The transformation from the sigmoid ILD curve in LLDp to the pyramid shape in ICx is partly understood. Both sides of the pyramid are bounded by inhibition (cf. Figure 4) (Peña \& Konishi 2002). However, the exact source of the inhibitory signal to ICx has not been identified. Unlike LLDp, LSO receives excitatory input from the ipsilateral side and inhibitory input from the contralateral side. The inhibitory input comes from the medial nucleus of the trapezoid body, which receives from globular bushy cells phase-locked spikes by end-bulb terminals. This arrangement makes LSO sensitive to both the amplitude and temporal aspects of the stimulus, such as amplitude modulations (see Oertel 1999, Grothe 2000 for review).

\section{INDEPENDENCE OF ITD AND ILD PROCESSING}

Auditory systems of humans and laboratory mammals process ITD and ILD in separate frequency ranges: low frequencies for ITD and high frequencies for ILD. Many studies show that humans localize sounds in azimuth best by using the ongoing ITD in low-frequency bands and ILD in high-frequency bands (Wightman 1992, Macpherson \& Middlebrooks 2002). Here, ongoing ITDs refers to the ITDs derived from phase-locked spikes in the spectral components of the signal. Humans can also use interaural temporal disparities in the envelope of amplitude-modulated high-frequency signals. Interaural differences in the arrival time of the first wave of signals or onset time are also usable for sound localization. However, given all these potential cues at once, humans generally select the ongoing ITD in lowfrequency bands and ILD in high-frequency bands, although individual differences occur (Macpherson \& Middlebrooks 2002). The ongoing ITD is preferred perhaps because $(a)$ the signal provides the multiple cycles for interaural comparison of phase-locked spikes, whereas it contains only one onset and offset time for comparison; (b) ILD has little influence on encoding of the ongoing ITD, especially when the signal is broadband (cat IC: Caird \& Klinke 1987; owl NL: Viete et al. 1997), whereas ILD affects the encoding of the onset time, owing to variation in spike latency with sound level.

In the owl, the independence of ITD from ILD is particularly important because ITD and ILD code for different coordinate axes. Also, the owl extracts both ITD and ILD in the same frequency range. For high frequencies such as $7 \mathrm{kHz}$, the maximal ILD can exceed $20 \mathrm{~dB}$ under free-field conditions (Moiseff 1989a, Keller 
et al. 1998). Viete et al. (1997) showed that the ITD selectivity of NL neurons was relatively immune to ILDs, provided that the signal was either broadband or tones matched to the neuron's best frequency. Deviations from the neuron's best frequency caused systematic shifts in its preferred ITD. The causes for these shifts appear to be in the inner ear where sound levels affect the propagation of phaselocked spikes when the stimulus frequency is different from the neuron's best frequency (Andersen et al. 1971). Somehow, the advancing and delaying effects of sound levels on phase-locked neurons cancel out each other when the signal is broadband. Also, NL neurons do not saturate at high sound levels, thus maintaining their ITD selectivity (Peña et al. 1996).

\section{AUDITORY SPATIAL RECEPTIVE FIELDS}

Many recent papers describe auditory spatial receptive fields for both free-field and virtual space in different brain areas of mammals (e.g., cat SOC: Tollin \& Yin 2002a,b; cat IC: Delgutte et al. 1999; cat auditory cortex: Brugge et al. 2001; ferret auditory cortex: Mrsic-Flogel et al. 2001; monkey auditory cortex: Recanzone et al. 2000). Receptive fields in mammals are not as small and sharply bounded as those of the owl's space-specific neurons. Also, mammalian receptive fields, particularly those in the cortex, expand in response to a rise in sound level. Nevertheless, analyses of these receptive fields, particularly with HRTF, established that the acoustical cues for their formation are ITDs in low frequencies, ILDs in high frequencies, and monaural spectral cues (e.g., Delgutte et al. 1999). Although mammals do not show conspicuous bilateral asymmetries in the position and structure of the ear opening and the pinna, monaural spectral cues confer elevational boundaries on the receptive fields of IC and cortical neurons (e.g., Imig et al. 1997, Xu et al. 1998, Schnupp et al. 2001).

The owl's space-specific neurons also predominantly represent the contralateral hemifield. However, both the left and right ICx and optic tectum contain neurons with receptive fields on the ipsilateral hemifield near the midline where the owl localizes sound most accurately (Knudsen et al. 1979, Knudsen \& Konishi 1979). The receptive field of a space-specific neuron in ICx, as studied by free-field methods of stimulation, consisted of an excitatory center and an inhibitory surround as in the visual system (Knudsen \& Konishi 1978b). An intracellular study of ICx showed that the excitatory center was attributable to EPSPs (excitatory postsynaptic potentials) and the surround to IPSPs (inhibitory postsynaptic potentials) and subthreshold EPSPs (Figure 5). The free-field study showed the strength of inhibition to decline with distance from the excitatory center, whereas the intracellular study showed an infinite extent of the inhibitory surrounds (Peña \& Konishi 2002). This difference is partly due to variances in the methods of stimulation. Dichotic stimulation with earphones can generate any large ITD or ILD that no free-field stimulation can produce. The apparent loss or weakening of inhibition with distance in azimuth observed in the free-field study is due to the depolarization corresponding to the first side peak, which the free-field study did not recognize. 


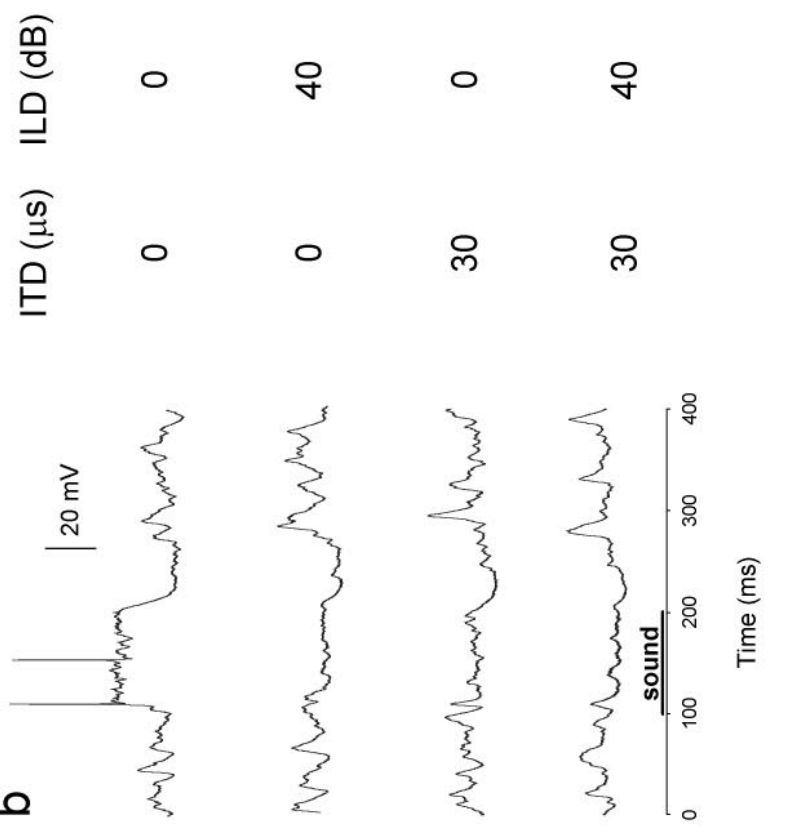

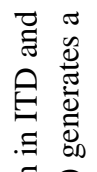

응

巳

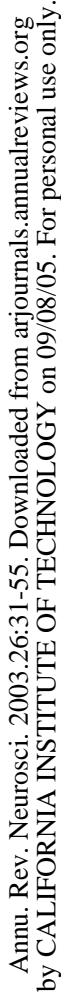

氜

월 궁

过是

$\approx$ क $\infty$

눙

证

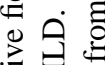

氖 氙

鸪

莫范

(ิ)

ن.

() 응

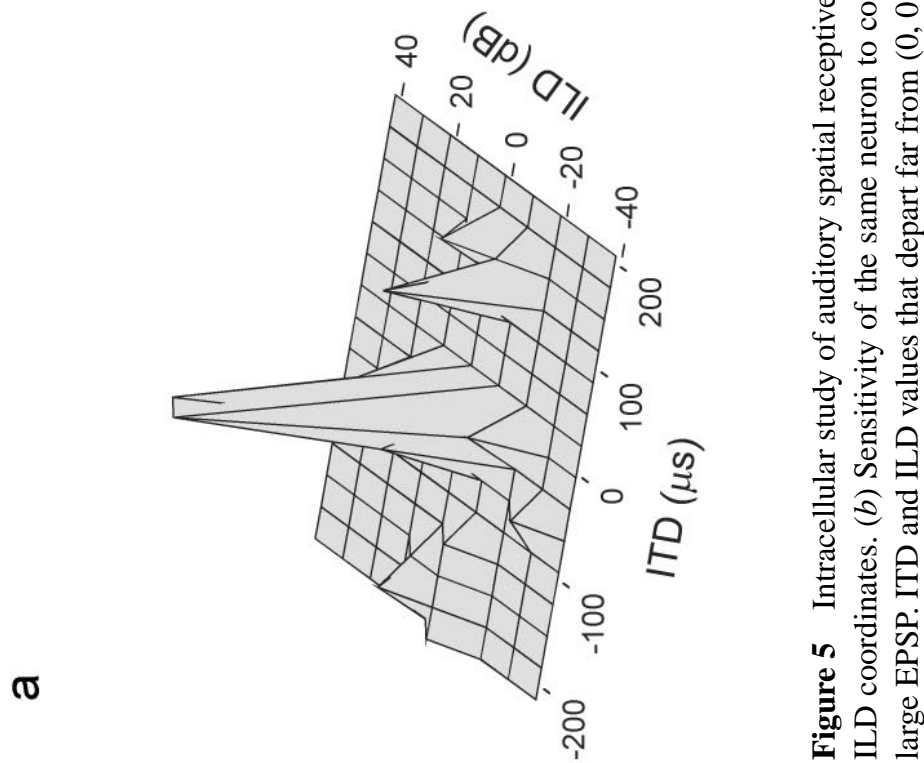


The location and dimensions of a neuron's receptive field excitatory center is determined by its selectivity for ITD-ILD pairs. ITD and ILD determines, respectively, the horizontal and vertical directions and dimensions of receptive fields (Moiseff \& Konishi 1981, Olsen et al. 1989). A recent HRTF study also lends support to this view (Euston \& Takahashi 2002). The intracellular study allowed us to analyze the sensitivity of space-specific neurons in ICx to combinations of ITD and ILD (Figure 5) (Peña \& Konishi 2001, 2002). Combination of the most favorable ITD and ILD generated supra-threshold EPSPs. Departures of either cue from this value reduced the EPSPs. ITDs or ILDs that were far from the best value caused either IPSPs or subthreshold EPSPs. Large ILDs including monaural stimulation always inhibited the neuron by hyperpolarization. Analysis of postsynaptic potentials for various ITD-ILD pairs showed that ICx neurons multiply postsynaptic potentials from the ITD and ILD pathways (Figure 6) (Peña \& Konishi 2001). It is interesting that Stern \& Colburn (1978) put forth the idea of multiplying neural signals for ITD and ILD to explain how humans resolve the ambiguity of localizing tones. This model processes ITDs by cross-correlation in one pathway and produces pyramid-shaped ILD functions in a separate pathway. Convergence of the two pathways produces a function that uniquely defines spatial directions. The similarity between the model and the owl is striking.

\section{THE OWL MODEL AND PROBLEMS OF CODING}

\section{Place or Ensemble Coding}

In the Jeffress model, a neuron's place represents a sound source direction. This scheme is the simplest form of place-coding or line-labeling. Population coding in its purest form uses spatial or temporal distributions of neuronal activities to encode different stimuli or stimulus features. Population coding in neurophysiology usually refers to a set of neurons that are broadly tuned to a stimulus or to one of its features with overlapping tuning curves. Examples include the trichromatic color system in the retina and the leeches' sensory neurons that collectively encode the position of tactile stimuli for evasive bending of the body (Lewis \& Kristan 1998). Recent papers argue that the Jeffress scheme does not apply to gerbils and guinea pigs (Schnupp 2000, McAlpine et al. 2001, Brand et al. 2002). The IC of guinea pigs and the MSO of gerbils contain low-frequency neurons

Figure 6 Multiplication creates sensitivity for ITD-ILD pairs. Analysis of postsynaptic potentials by the method of single value decomposition shows that the spacespecific neuron multiplies the postsynaptic potentials from ITD and ILD inputs. $(B)$ The input functions identified by the method closely resemble the shapes of the neuron's ITD and ILD curves. (A) Multiplication of these functions produces a distribution of postsynaptic potentials similar to the original data (adapted from Peña \& Konishi 2001). 

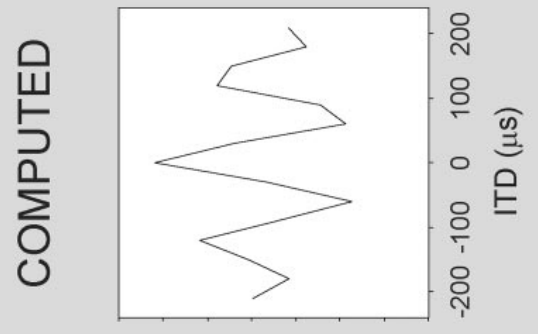

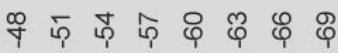
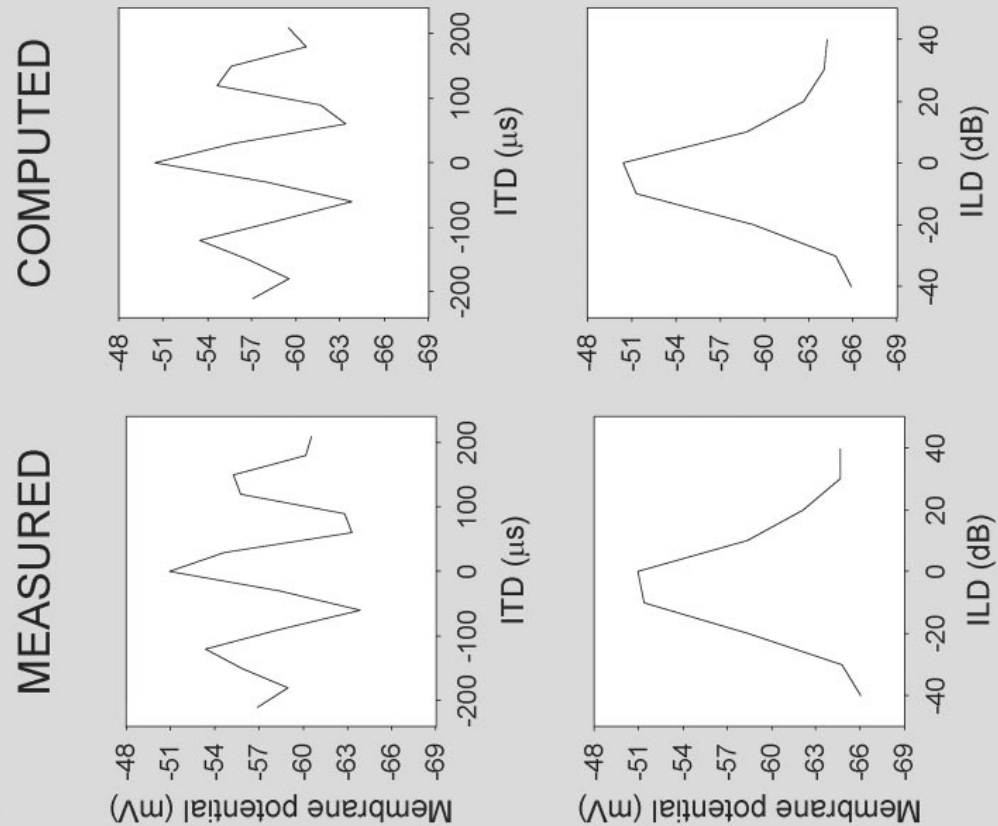

守它志

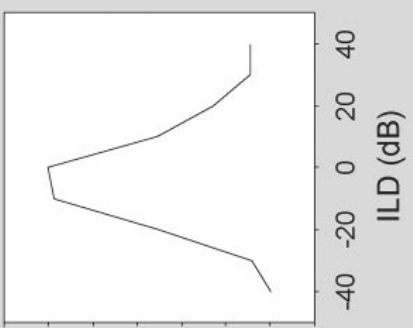

守 ᄃு

$m$

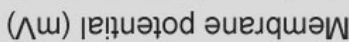

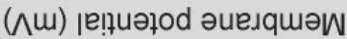

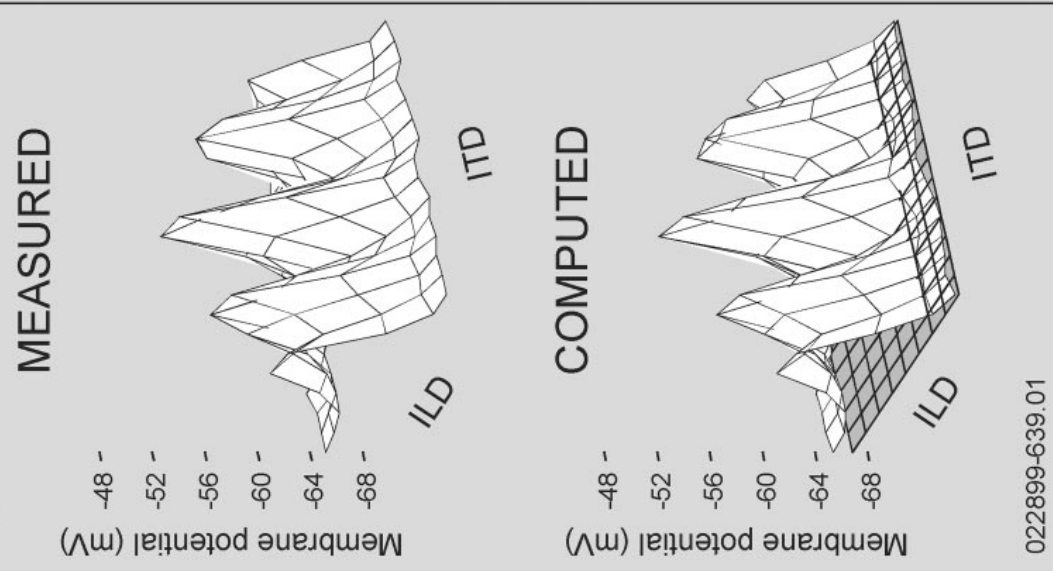


whose ITDi far exceeds the normal range of ITDs. In the guinea pig's IC, the slopes of ITD curves are steep across the midline and within the biologically relevant range of ITD. McAlpine et al. (2001) argue that this population of neurons might work like the color-coding system, in which the differential activities of the three receptor types determine different hues. The sum of spike rates from overlapping ITD tuning curves of neurons might encode azimuth.

Jeffress was aware of the simplicity of his model when he wrote,

"Obviously figure 1 is intended merely to illustrate a principle. Any such center, if it does exist, must comprise a large number of secondary fibers, and probably hundreds of tertiary fibers for each secondary. This means that a pure tone of low frequency heard binaurally will innervate a considerable group of tertiary fibers, and that a shift in the direction of the source will shift this mass of activity." (Jeffress 1948, p. 37)

The mass of activity comes from neurons tuned to the same or similar ITDs. If so, this response is not fundamentally different from ensemble coding. Because ITD appears to vary continuously along the dorsoventral axis in the owl's NL, one would expect a mass of activity peaked at the neuron population tuned to the stimulus ITD. The center of activity can be wide or narrow depending on the degree of ITD tuning of individual neurons. The width of ITD peaks in most tonotopically organized nuclei of the owl is correlated with the period of the stimulus tone or the neuron's best frequency (Carr \& Konishi 1990, Fujita \& Konishi 1991, Wagner et al. 2002). ITD tuning curves overlap each other more in low-frequency neurons than in high-frequency neurons. Therefore, the owl's auditory system might encode ITDs by ensembles of neurons at the level of primary coincidence detectors and in tonotopically organized nuclei.

Sensory coding is a synthetic process. We often do not know what the end product of the synthesis is. Without this knowledge, we may not be able to appreciate phenomena that occur in lower centers. The width of ITD peaks is independent of frequency in some high-order neurons in rabbits and in all space-specific neurons in owls (cf. Figure 2) (Fujita \& Konishi 1991, Fitzpatrick et al. 1997, Fitzpatrick $\&$ Kuwada 2001). In the owl, the ICcl neurons tuned to the same ITDi project to single ICx neurons (cf. Figure 3). Thus, population activities in lower centers is organized to create in higher centers new labeled lines that encode the stimulus less ambiguously and more precisely than each member of the ensemble (Wagner et al. 1987, Takahashi 1989, Fitzpatrick et al. 1997). Such a code transformation occurs in other sensory modalities (e.g., Perez-Orive et al. 2002).

\section{Maps or No Maps}

Maps of auditory space, or their absence, also present an excellent example for the unpredictability of coding schemes. The space-specific neurons form a map of auditory space in ICx (Knudsen \& Konishi 1978a). The map is isomorphic because the relationships between spatial directions are maintained in the cellular 
arrays. However, neither the study of higher nor lower stations in the owl's auditory system could have predicted the presence of a map in ICx. We failed to find such a map in Field L, a forebrain area, despite the presence of many space-specific neurons (Knudsen et al. 1977). We could not have predicted a map in ICx had we studied ITD-selective neurons in ICcc (Wagner et al. 2002). Similarly, many attempts have failed to find maps of auditory space within the mammalian brain with the exception of maps in the superior colliculus of ferrets, cats, guinea pigs (Middlebrooks \& Knudsen 1984, Withington 1994, King \& Hutchings 1987), and the external nucleus of the inferior colliculus of guinea pigs (Binns et al. 1992). Therefore, some authors have suggested other methods of coding auditory space such as direction-dependent changes in response latencies and direction-dependent temporal patterns of spike discharge in the cat's auditory cortex (e.g., Brugge et al. 2001, Furukawa \& Middlebrooks 2002).

The example of the owl's auditory space map is often cited without referring to the fact that the owl can localize sounds without the map. Complete or partial lesions of the map render the owl incapable of localizing sound, respectively, in the contralateral hemifield and in the spatial coordinates encoded by the selectively damaged areas. However, the owl's ability to localize sounds returns after a while (Wagner 1993, Knudsen et al. 1993). This mapped pathway mediates fast responses in sound localization. When this pathway is disrupted, the owl appears to use a second separate pathway that goes from ICcl to the forebrain by the thalamus (Knudsen et al. 1993; Cohen \& Knudsen 1994, 1995, 1998; Cohen et al. 1998). This pathway contains separate clusters of space-specific neurons tuned to similar spatial and dichotic coordinates, but no maps have been described to date. Lesions of both pathways completely disable the owl to localize sounds in the contralateral hemifield. Thus, the same animal and the same brain appear to be able to use either the mapped or nonmapped neural systems to localize sounds.

\section{ACKNOWLEDGMENTS}

I dedicate this article to the late Max Cowan who started this review series. I thank Jose Luis Peña, Sharad Shanbhag, and Bjorn Christianson for reading the manuscript. The preparation of this review was supported by NIH grant DC00134.

\section{The Annual Review of Neuroscience is online at http://neuro.annualreviews.org}

\section{LITERATURE CITED}

Adolphs R. 1993. Bilateral inhibition generates neuronal responses tuned to interaural level differences in the auditory brain stem of the barn owl. J. Neurosci. 13:3647-68

Agmon-Snir H, Carr C, Rinzel J. 1998. The role of dendrites in auditory coincidence detection. Nature 393:268-72
Albeck Y, Konishi M. 1995. Responses of neurons in the auditory pathway of the barn owl to partially correlated binaural signals. J. Neurophysiol. 74:1689-700

Anderson DJ, Rose JE, Hind JE, Brugge JF. 1971. Temporal position of discharge in single auditory nerve fibers within the cycle of a 
sine-wave stimulus: frequency and intensity effects. J. Acoust. Soc. Am. 49:1131-39

Batra R, Kuwada S, Fitzpatrick DC. 1997. Sensitivity to interaural temporal disparities of low- and high-frequency neurons in the superior olivary complex. II. Coincidence detection. J. Neurophysiol. 78:1237-47

Beckius GE, Batra R, Oliver DL. 2000. Axon from anteroventral cochlear nucleus that terminates in medial superior olive of the cat: observations related to delay lines. $\mathrm{J}$. Neurosci. 19:3146-61

Binns KE, Grant S, Withington DJ, Keating MJ. 1992. A topographic representation of auditory space in the external nucleus of the inferior colliculus of the guinea-pig. Brain Res. 589:231-42

Blauert J, Lindemann W. 1986. Spatial mapping of intercranial auditory events for various degrees of interaural coherence. J. Acoust. Soc. Am. 79:806-13

Brainard MD, Knudsen EI, Esterly SD. 1992. Neural derivation of sound source location: resolution of spatial ambiguity in binaural cues. J. Acoust. Soc. Am. 91:1015-27

Brand A, Behrend O, Marquardt T, McAlpine D, Grothe B. 2002. Precise inhibition is essential for microsecond interaural time difference coding. Nature 417:543-47

Bruckner S, Hyson RL. 1998. Effect of GABA on the processing of interaural time differences in nucleus laminaris neurons in the chick. Eur. J. Neurosci. 10:3438-50

Brugge JF, Reale RA, Jenison RL, Schnupp J. 2001. Auditory cortical spatial receptive fields. Audiol. Neurootol. 6:173-77

Caird D, Klinke R. 1987. Processing of interaural time and intensity differences in the cat inferior colliculus. Exp. Brain. Res. 68:37992

Carr CE, Boudreau RE. 1991. Central projections of auditory nerve fibers in the barn owl. J. Comp. Neurol. 314:306-18

Carr CE, Boudreau RE. 1993. Organization of the nucleus magnocellularis and the nucleus laminaris in the barn owl: encoding and measuring interaural time differences. J. Comp. Neurol. 334:337-55
Carr CE, Boudreau RE. 1996. Development of the time coding pathways in the auditory brain stem of the barn owl. J. Comp. Neurol. 373:467-83

Carr C, Code R. 2000. The central auditory system in reptiles and birds. In Comparative Hearing: Birds and Reptiles, ed. R Dooling, R Fay, A Popper, pp. 1-400. New York: Springer

Carr CE, Friedman MA. 1999. Evolution of time coding systems. Neural Comput. 11:120

Carr CE, Fujita I, Konishi M. 1989. Distribution of GABAergic neurons and terminals in the auditory system of the barn owl. J. Comp. Neurol. 286:190-207

Carr CE, Konishi M. 1988. Axonal delay lines for time measurement in the owl's brainstem. Proc. Natl. Acad. Sci. USA 85:8311-15

Carr CE, Konishi M. 1990. A circuit for detection of interaural time differences in the brainstem of the barn owl. J. Neurosci. 10: 3227-46

Cohen Y, Knudsen EI. 1994. Auditory tuning for spatial cues in the barn owl basal ganglia. J. Neurophysiol. 72:285-98

Cohen Y, Knudsen EI. 1995. Binaural tuning of auditory units in the forebrain archistriatal gaze fields of the barn owl: local organization but no space map. J. Neurosci. 15:5152-68

Cohen Y, Knudsen EI. 1998. Representation of binaural spatial cues in Field L of the barn owl forebrain. J. Neurophysiol. 79:879-90

Cohen Y, Miller GL, Knudsen EI. 1998. Forebrain pathway for auditory space processing in the barn owl. J. Neurophysiol. 79:891-902

Colburn HS, Han Y, Culotta CP. 1990. Coincidence model of MSO responses. Hear. Res. 49:335-46

Delgutte B, Joris PX, Litovsky RY, Yin TC. 1999. Receptive fields and binaural interactions for virtual-space stimuli in the cat inferior colliculus. J. Neurophysiol. 81:283351

Egnor SER. 2000. The role of spectral cues in sound localization by the barn owl. $\mathrm{PhD}$ thesis. Calif. Inst. Technol. 131 pp.

Egnor SER. 2001. Effects of binaural 
decorrelation on neural and behavioral processing of interaural level differences in the barn owl (Tyto alba). J. Comp. Physiol. A 187:589-95

Euston DR, Takahashi TT. 2002. From spectrum to space: the contribution of level difference cues to spatial receptive fields in the barn owl inferior colliculus. J. Neurosci. 22:284-93

Fitzpatrick DC, Batra R, Stanford TR, Kuwada S. 1997. A neuronal population code for sound localization. Nature 388:871-74

Fitzpatrick DC, Kuwada S. 2001. Tuning to interaural time differences across frequency. $J$. Neurosci. 21:4844-51

Fujita I, Konishi M. 1991. The role of GABAergic inhibition in processing of interaural time difference in the owl's auditory system. $J$. Neurosci. 11:722-39

Funabiki K, Koyano K, Ohmori H. 1998. The role of GABAergic inputs for coincidence detection in the nucleus laminaris of the chick. J. Physiol. (Lond.) 508:851-69

Furukawa S, Middlebrooks JC. 2002. Cortical representation of auditory space: information-bearing features of spike patterns. $J$. Neurophysiol. 87:1749-62

Goldberg JM, Brown PB. 1969. Responses of binaural neurons of dog superior olivary complex to dichotic tonal stimuli: some physiological mechanisms of sound localization. J. Neurophysiol. 32:613-36

Grothe B. 2000. The evolution of temporal processing in the medial superior olive, an auditory brainstem structure. Progr. Neurobiol. 61:581-610

Grothe B, Sanes DH. 1993. Bilateral inhibition by glycinergic afferents in the medial superior olive. J. Neurophysiol. 69:1192-96

Grothe B, Sanes DH. 1994. Synaptic inhibition influences the temporal coding properties of medial superior olivary neurons: an in vitro study. J. Neurosci. 14:1701-9

Han Y, Colburn HS. 1993. Point-neuron model for binaural interaction in MSO. Hear. Res. 68:115-30

Imig T, Poirier JP, Irons WA, Samson FK. 1997. Monaural spectral contrast mechanism for neural sensitivity to sound direction in the medial geniculate body of the cat. J. Neurophysiol. 78:2754-71

Jeffress LA. 1948. A place theory of sound localization. J. Comp. Physiol. Psychol. 41:3539

Jeffress LA, Blodgett HC, Deatherage BH. 1962. Effect of interaural correlation on the precision of centering a noise. J. Acoust. Soc. Am. 32:1122-23

Jeffress LA, Robinson DE. 1962. Formulas for the coefficient of interaural correlation for noise. J. Acoust. Soc. Am. 34:165859

Jhaveri S, Morest D. 1982. Neuronal architecture in nucleus magnocellularis of the chicken with observations on nucleus laminaris: a light and electron microscope study. Neuroscience 7:809-36

Joris PX, Smith PH, Yin TC. 1998. Coincidence detection in the auditory system: 50 years after Jeffress. Neuron 21:1235-38

Joseph AW, Hyson RL. 1993. Coincidence detection by binaural neurons in the chick brain stem. J. Neurophysiol. 69:1197-211

Keller CH, Hartung K, Takahashi TT. 1998. Head-related transfer functions of the barn owl: measurement and neural responses. Hear. Res. 118:13-34

Keller CH, Takahashi TT. 1996. Binaural crosscorrelation predicts the responses of neurons in the owl's auditory space map under conditions simulating summing localization. $J$. Neurosci. 16:4300-9

King AJ, Hutchings ME. 1987. Spatial response properties of acoustically responsive neurons in the superior colliculus of the ferret: a map of auditory space. J. Neurophysiol. 57:596625

Knudsen EI. 2002. Instructed learning in the auditory localization pathway of the barn owl. Nature 417:322-28

Knudsen EI, Blasdel GG, Konishi M. 1979. Sound localization by the barn owl (Tyto alba) measured with the search coil technique. J. Comp. Physiol. 133:1-11

Knudsen EI, Knudsen PF. 1983. Space-mapped auditory projections from the inferior 
colliculus to the optic tectum in the barn owl (Tyto alba). J. Comp. Neurol. 218:187-96

Knudsen EI, Knudsen PF, Masino T. 1993. Parallel pathways mediating both sound localization and gaze control in the forebrain and midbrain of the barn owl. J. Neurosci. 13:2837-52

Knudsen EI, Konishi M. 1978a. Space and frequency are represented separately in auditory midbrain of the owl. J. Neurophysiol. 41:870-84

Knudsen EI, Konishi M. 1978b. Centersurround organization of auditory receptive fields in the owl. Science 202:778-80

Knudsen EI, Konishi M. 1979. Mechanisms of sound localization in the barn owl (Tyto alba). J. Comp. Physiol. 133:13-21

Knudsen EI, Konishi M, Pettigrew JD. 1977. Receptive fields of auditory neurons in the owl. Science 198:1278-80

Konishi M. 1995. Neural mechanisms of auditory image formation. In The Cognitive Neurosciences, ed. MS Gazzaniga, pp. 26977. Boston: MIT Press

Köppl C. 1997a. Frequency tuning and spontaneous activity in the auditory nerve and cochlear nucleus magnocellularis of the barn owl, Tyto alba. J. Neurophysiol. 77:36477

Köppl C. 1997b. Phase locking to high frequencies in the auditory nerve and cochlear nucleus magnocellularis of the barn owl, Tyto alba. J. Neurosci. 17:3312-21

Köppl C, Gleich O, Manley GA. 1993. An auditory fovea in the barn owl cochlea. J. Comp. Physiol. A 171:695-704

Kubke MF, Carr CE. 2000. Development of the auditory brainstem of birds: comparison between barn owls and chickens. Hear. Res. 147:1-20

Kubke MF, Massoglia DP, Carr CE. 2002. Developmental changes underlying the formation of the specialized time coding circuits in barn owls (Tyto alba). J. Neurosci. 22:767179

Lachica EA, Rubsamen R, Rubel EW. 1994. GABAergic terminals in nucleus magnocellularis and laminaris originate from the superior olivary nucleus. J. Comp. Neurol. 348:403-18

Lewis JE, Kristan WB. 1998. A neuronal network for computing population vectors in the leech. Nature 391:76-79

Manley GA, Köppl C, Konishi M. 1988. A neural map of interaural intensity differences in the brainstem of the barn owl. J. Neurosci. 8:2665-76

Mazer JA. 1998. How the owl resolves auditory coding ambiguity. Proc. Natl. Acad. Sci. USA 95:10,932-37

Macpherson EA, Middlebrooks JC. 2002. Listener weighting of cues for lateral angles: the duplex theory of sound localization revisited. J. Acoust. Soc. Am. 111:2219-36

McAlpine D, Jiang D, Palmer AR. 2001. A neural code for low-frequency sound localization in mammals. Nat. Neurosci. 4:396-401

Middlebrooks JC, Knudsen EI. 1984. A neural code for auditory space in the cat's superior colliculus. J. Neurosci. 10:2621-34

Mogdans J, Knudsen EI. 1994. Representation of interaural level difference in the VLVp, the first site of binaural comparison in the barn owl auditory-system. Hear. Res. 74:148-64

Moiseff A. 1989a. Binaural disparity cues available to the barn owl for sound localization. $J$. Comp. Physiol. 164:629-36

Moiseff A. 1989b. Bi-coordinate sound localization by the barn owl. J. Comp. Physiol. 164:637-44

Moiseff A, Konishi M. 1981. Neuronal and behavioral sensitivity to binaural time difference in the owl. J. Neurosci. 1:40-48

Mori K. 1997. Across-frequency nonlinear inhibition by GABA in processing of interaural time difference. Hear. Res. 111:17-30

Mrsic-Flogel TD, King AJ, Jenison RL, Schnupp JW. 2001. Listening through different ears alters spatial response fields in ferret primary auditory cortex. J. Neurophysiol. 86:1043-46

Oertel D. 1999. The role of timing in the brain stem auditory nuclei of vertebrates. Annu. Rev. Physiol. 61:497-519

Olsen JF, Knudsen EI, Esterly SD. 1989. Neural maps of interaural time and intensity 
differences in the optic tectum of the barn owl. J. Neurosci. 9:2591-605

Overholt EM, Rubel EW, Hyson RL. 1992. A circuit for coding interaural time differences in the chick brainstem. J. Neurosci. 12:1698708

Parameshwaran S, Carr CE, Perney TM. 2001. Expression of the Kv3.1 potassium channel in the avian auditory brainstem. J. Neurosci. 21:485-94

Parks TN, Rubel EW. 1975. Organization and development of brain stem auditory nuclei of the chicken: organization of projections from n. magnocellularis to n. laminaris. J. Comp. Neurol. 164:435-48

Peña JL, Konishi M. 2000. Cellular mechanisms for resolving phase ambiguity in the owl's inferior colliculus. Proc. Natl. Acad. Sci. USA 97:11,787-92

Peña JL, Konishi M. 2001. Auditory spatial receptive fields created by multiplication. Science 292:249-52

Peña JL, Konishi M. 2002. From postsynaptic potentials to spikes in the genesis of auditory spatial receptive fields. J. Neurosci. 22:565258

Peña JL, Viete S, Albeck Y, Konishi M. 1996. Tolerance to sound intensity of binaural coincidence detection in the nucleus laminaris of the owl. J. Neurosci. 16:7046-54

Peña JL, Viete S, Funabiki K, Saberi K, Konishi M. 2001. Cochlear and neural delays for coincidence detection in owls. J. Neurosci. 21:9455-59

Perez-Orive J, Mazor O, Turner GC, Cassenaer S, Wilson RI, Laurent G. 2002. Oscillations and sparsening of odor representation in the mushroom body. Science 297:359-65

Poganiatz I, Nelken I, Wagner H. 2001. Soundlocalization experiments with barn owls in virtual space: influence of interaural time difference on head-turning behavior. J. Assoc. Res. Otolaryngol. 2:1-21

Poganiatz I, Wagner H. 2001. Sound-localization experiments with barn owls in virtual space: influence of broadband interaural level difference on head-turning behavior. $J$. Comp. Physiol. A 187:225-33
Recanzone GH, Guard DC, Phan ML, Su TK. 2000. Correlation between the activity of single auditory cortical neurons and soundlocalization behavior in the macaque monkey. J. Neurophysiol. 83:2723-39

Reyes AD, Rubel EW, Spain WJ. 1996. In vitro analysis of optimal stimuli for phaselocking and time-delayed modulation of firing in avian nucleus laminaris neurons. $J$. Neurosci. 16:993-1007

Rose JE, Gross NB, Geisler CD, Hind JE. 1966. Some neural mechanisms in the inferior colliculus of the cat which may be relevant to localization of a sound source. J. Neurophysiol. 29:288-314

Saberi K, Farahbod H, Konishi M. 1998a. How do owls localize interaurally phaseambiguous signals. Proc. Natl. Acad. Sci. USA 95:6465-68

Saberi K, Takahashi Y, Farahbod H, Konishi M. 1999. Neural basis of an auditory illusion and its elimination owls. Nat. Neurosci. 2:656-59

Saberi K, Takahashi Y, Konishi M, Albeck Y, Arthur BJ, Farahbod H. 1998b. Effects of interaural decorrelation on neural and behavioral detection of spatial cues. Neuron 21:789-98

Schnupp JW. 2000. Of delays, coincidences and efficient coding for space in the auditory pathway. Trends Neurosci. 24:677-78

Schnupp JW, Mrsic-Flogel DT, King AJ. 2001. Linear processing of spatial cues in primary auditory cortex. Nature 414:200-4

Simon J, Carr CE, Shamma S. 1999. A dendritic model of coincidence detection in the avian brainstem. Neurocomputing 26:263-69

Smith PH, Joris PX, Yin TC. 1993. Projections of physiologically characterized spherical bushy cell axons from the cochlear nucleus of the cat: evidence for delay lines to the medial superior olive. J. Comp. Neurol. 331:245-60

Smith Z. 1981. Organization and development of brain stem auditory nuclei of the chicken: dendritic development in n. laminaris. $J$. Comp. Neurol. 203:309-33

Spitzer MW, Semple MN. 1995. Neurons sensitive to interaural phase disparity in gerbil 
superior olive: diverse monaural and temporal response properties. J. Neurophysiol. 73:1668-90

Stern RM, Colburn HS. 1978. Theory of binaural interaction based on auditory-nerve data. IV. A model for subjective lateral position. $J$. Acoust. Soc. Am. 64:127-40

Sullivan WE. 1985. Classification of response patterns in cochlear nucleus of barn owl: correlation with functional response properties. J. Neurophysiol. 53:201-16

Sullivan WE, Konishi M. 1984. Segregation of stimulus phase and intensity coding in the cochlear nucleus of the owl. J. Neurosci. 4:1787-99

Takahashi T, Konishi M. 1988a. Projections of the cochlear nuclei and nucleus laminaris to the inferior colliculus of the barn owl. $J$. Comp. Neurol. 274:190-211

Takahashi T, Konishi M. 1988b. Projections of nucleus angularis and nucleus laminaris to the lateral lemniscal nuclear complex of the barn owl. J. Comp. Neurol. 274:21238

Takahashi T, Wagner H, Konishi M. 1989. Role of commissural projections in the representation of bilateral auditory space in the barn owl's inferior colliculus. J. Comp. Neurol. 281:545-54

Takahashi TT. 1989. Construction of an auditory space map. Ann. N.Y. Acad. Sci. 563:101-13

Takahashi TT, Barberini CL, Keller CH. 1995. An anatomical substrate for the inhibitory gradient in the VLVp of the owl. J. Comp. Neurol. 358:294-304

Takahashi TT, Keller CH. 1992. Commisural connections mediate inhibition for the computation of interaural level difference in the barn owl. J. Comp. Physiol. A 170:16169

Takahashi TT, Konishi M. 1986. Selectivity for interaural time difference in the owl's midbrain. J. Neurosci. 6:3413-22

Takahashi TT, Moiseff A, Konishi M. 1984. Time and intensity cues are processed independently in the auditory system of the owl. J. Neurosci. 4:1781-86
Takahashi Y, Konishi M. 2002. Manipulation of inhibition in the owl's nucleus laminaris and its effects on optic tectum neurons. Neuroscience 111:373-78

Tollin DJ, Yin CT. 2002a. The coding of spatial location by single units in the lateral superior olive of the cat. 1. Spatial receptive fields in azimuth. J. Neurosci. 22:1454-67

Tollin DJ, Yin CT. 2002b. The coding of spatial location by single units in the lateral superior olive of the cat. II. The determinants of spatial receptive fields in azimuth. $J$. Neurosci. 22:1468-79

Trahiotis C, Stern RM. 1994. Across-frequency integration in lateralization of complex binaural stimuli. J. Acoust. Soc. Am. 96:38046

Trussell LO. 1999. Synaptic mechanisms for coding timing in auditory neurons. Annu. Rev. Physiol. 61:477-96

Viete S, Peña JL, Konishi M. 1997. The effects of interaural intensity difference on the processing of interaural time difference in the owl's nucleus laminaris. J. Neurosci. $17: 1815-24$

Wagner H. 1993. Sound-localization deficits induced by lesions in the barn owl's auditory space map. J. Neurosci. 13:371-86

Wagner H, Takahashi TT, Konishi M. 1987. Representation of interaural time difference in the central nucleus of the barn owl's inferior colliculus. J. Neurosci. 7:310516

Wagner H, Mazer JA, von Campenhausen M. 2002. Response properties of neurons in the core of the central nucleus of the inferior colliculus of the barn owl. Eur. J. Neurosci. 15:1343-52

Wightman FL. 1992. The dominant role of low-frequency interaural time differences in sound localization. J. Acoust. Soc. Am. 91: 1648-61

Wild JM, Kubke MF, Carr CE. 2001. Tonotopic and somatotopic representation in the nucleus basalis of the barn owl, Tyto alba. Brain Behav. Evol. 57:39-62

Withington DJ, Binns KE, Ingham NJ, Thorton SK. 1994. Plasticity in the superior collicular 
auditory space map of adult guinea-pigs. Exp. Physiol. 79:319-25

Xu L, Furukawa S, Middlebrooks JC. 1998. Sensitivity to sound-source elevation in nontonotopic auditory cortex. J. Neurophysiol. 80:882-94

Yang L, Monsivais P, Rubel EW. 1999. The superior olivary nucleus and its influence on nucleus laminaris: a source of inhibitory feedback for coincidence detection in the avian auditory brainstem. J. Neurosci. 19:231325

Yin TC, Chan JC. 1990. Interaural time sensitivity in medial superior olive of cat. $\mathrm{J}$. Neurophysiol. 64:465-88

Yin TC, Chan JC, Carney LH. 1987. Effects of interaural time delays of noise stimuli on low-frequency cells in the cat's inferior colliculus. III. Evidence for cross-correlation. $J$. Neurophysiol. 58:562-83

Yin TC, Chan JC, Irvine DR. 1986. Effects of interaural time delays of noise stimuli on low-frequency cells in the cat's inferior colliculus. I. Responses to wideband noise. J. Neurophysiol. 55:280-300

Yin TC, Kuwada S. 1983. Binaural interaction in low-frequency neurons in inferior colliculus of the cat. III. Effects of changing frequency. J. Neurophysiol. 50:102042

Young SR, Rubel EW. 1983. Embryogenesis of arborization pattern and topography of individual axons in n. laminaris of the chicken brain-stem. J. Comp. Neurol. 254:425-59 

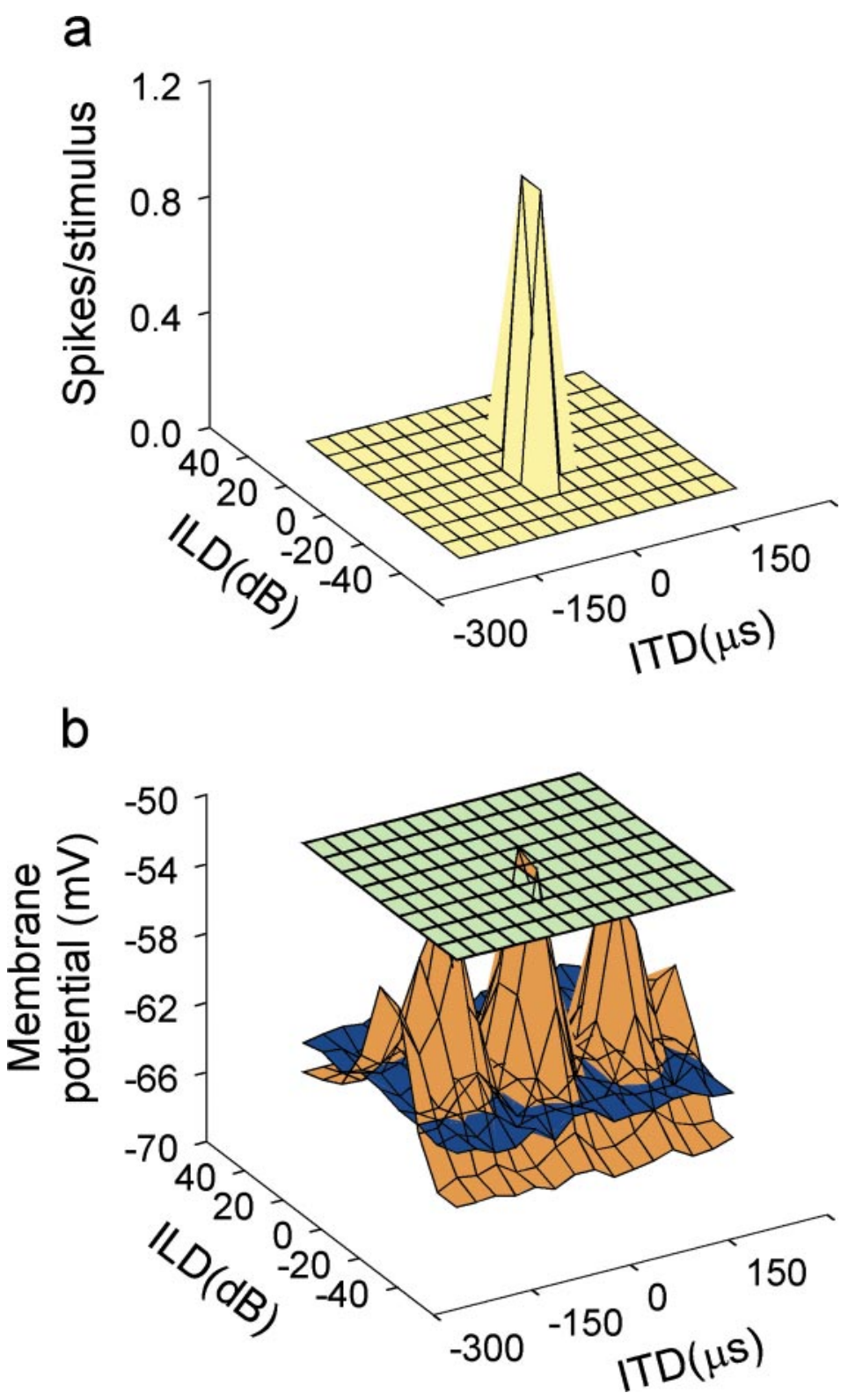

Figure 4 Thresholding for less ambiguous and smaller receptive fields. ITD and ILD responses of single neurons are plotted in three dimensions. (a) Only the main peak is present in spike rate data. (b) The first side peak (brown surface) is prominent in postsynaptic potential data. The blue surface indicates the resting potential level and buff surface the spiking threshold. Both ITD and ILD peaks are narrower in spike rates than in postsynaptic potentials (adapted from Peña \& Konishi 2002). 
R

Annual Review of Neuroscience

Volume 26, 2003

\section{CONTENTS}

PAIN MEChanisms: LABELED LINES VERSUS CONVERGENCE IN Central Processing, A.D. (Bud) Craig

CODING OF AUdiTORY SPACE, Masakazu Konishi 31

DECIPHERING THE GENETIC BASIS OF SPEECH AND LANGUAGE DISORDERS, Simon E. Fisher, Cecilia S.L. Lai, and Anthony P. Monaco 57

EPIDEMIOLOGY OF NEURODEGENERATION, Richard Mayeux 81

Novel Neural Modulators, Darren Boehning and Solomon H. Snyder 105

The Neurobiology of Visual-SacCAdic DeCision MaKing, Paul W. Glimcher

COLOR VISION, Karl R. Gegenfurtner and Daniel C. Kiper

NEW INSIGHTS INTO THE DIVERSITY AND FUNCTION OF NEURONAL IMMUNOGLOBULIN SUPERFAMILY MOLECULES, Geneviève Rougon and Oliver Hobert

Breathing: Rhythmicity, Plasticity, ChEMosensitivity, Jack L. Feldman, Gordon S. Mitchell, and Eugene E. Nattie

PROTOFIBRILS, PORES, FibRILS, AND NEURODEGENERATION: SEPARATING THE RESPONSIBLE PROTEIN AGgREGATES FROM THE INNOCENT BYSTANDERS, Byron Caughey and Peter T. Lansbury, Jr.

SELECTIVITY IN NEUROTROPHIN SignALING: THEME AND VARIATIONS, Rosalind A. Segal

BRAIN REPRESENTATION OF OBJECT-CENTERED SPACE IN MONKEYS AND HuMANS, Carl R. Olson

Generating THE Cerebral Cortical Area MAP, Elizabeth A. Grove and Tomomi Fukuchi-Shimogori

INFERENCE AND COMPUTATION WITH POPULATION CODES, Alexandre Pouget, Peter Dayan, and Richard S. Zemel

MoleCUlar APPROACHES to SPINAL CORD RePAIR, Samuel David and Steve Lacroix

Cell Migration In THE Forebrain, Oscar Marín and

John L.R. Rubenstein 
Cell-Cell Signaling During Synapse Formation in the CNS, Peter Scheiffele

SignALING AT THE GROWTH CONE: LigAND-RECEPTOR COMPLEXES AND THE CONTROL OF AXON GROWTH AND GUIDANCE, Andrea B. Huber, Alex L. Kolodkin, David D. Ginty, and Jean-François Cloutier

NotCH AND PRESENILIN: REgUlATED INTRAMEMBRANE PROTEOLYSIS Links DEVElopMENT AND DEGENERATION, Dennis Selkoe and Raphael Kopan

THE BIOLOGY OF EPILEPSY GENES, Jeffrey L. Noebels

Human NeURodegenerative Disease Modeling USING DROSOPHILA, Nancy M. Bonini and Mark E. Fortini

PROGRESS TOWARD UNDERSTANDING THE GENETIC AND BIOCHEMICAL MECHANISMS OF INHERITED PHOTORECEPTOR DEGENERATIONS, Laura R. Pacione, Michael J. Szego, Sakae Ikeda, Patsy M. Nishina, and Roderick R. McInnes

Cell Biology of the Presynaptic Terminal, Venkatesh N. Murthy and Pietro De Camilli

INDEXES

Subject Index

Cumulative Index of Contributing Authors, Volumes 17-26

Cumulative Index of Chapter Titles, Volumes 17-26

\section{ERRATA}

An online log of corrections to Annual Review of Neuroscience chapters (if any, 1997 to the present) may be found at http://neuro.annualreviews.org/ 